\title{
REGISTROS DE ENFERMAGEM EM HOME CARE: SUBSÍDIOS DA AUDITORIA DE ENFERMAGEM
}

NURSING HOME CARE RECORDS: RELIABLE SOURCES FOR AUDITING

\author{
Isadora Cid Dantas', Márcia Gomes Duarte², \\ Ester de Almeida Souza ${ }^{3}$, Elzo Pereira Pinto Junior ${ }^{4}$
}

'Enfermeira. Auditora do Setor Contas Médicas de uma empresa privada. Salvador, Bahia, Brasil. isadora_cid@hotmail.com ${ }^{2}$ Engenheira Civil. Mestre em Administração. Servidora da Diretoria de Vigilância Sanitária Ambiental da Secretaria de Saúde do Estado da Bahia (DIVISA/SESAB). Salvador, Bahia, Brasil. marcia.duarte@saude.ba.gov.br ${ }^{3}$ Enfermeira. Doutora em Saúde Pública. Professora na Universidade Federal da Bahia. Salvador, Bahia, Brasil. esterzinhasouza@ig.com.br ${ }^{4}$ Fisioterapeuta. Mestre em Saúde Coletiva. Professor na Universidade Federal da Bahia. Salvador, Bahia, Brasil. elzojr@hotmail.com

RESUMO I Objetivo: Investigar a produção científica relacionada a auditoria de enfermagem, analisando o seu papel na organização do registro de enfermagem nos serviços de Home Care. Método: Trata-se de uma revisão narrativa de literatura. Os dados foram coletados utilizando a base de dados Scientific Electronic Library Online (SCIELO); Literatura Latino Americana e do Caribe em ciências da saúde (LILACS); Biblioteca virtual de saúde (BSV), além de livros, dissertações e teses encontradas no acervo da Biblioteca de Saúde da UFBA, com associação dos descritores: registros de enfermagem, auditoria de enfermagem, serviço de assistência domiciliar. Resultados: Foram selecionados 14 artigos, publicados no período de 2001 a 2015. Os resultados foram categorizados nos seguintes grupos: "auditoria de serviços de saúde e auditoria de enfermagem"; "características dos registros de enfermagem"; "aspectos históricos e operacionais dos serviços de home care"; "principais motivos para glosas em home care". Conclusão: A revisão da literatura apontou que os serviços de Home Care devem dispor de serviços de saúde integrais, dando suporte aos clientes em seus domicílios, permitindo cuidados de forma segura, confortável e humanizada. Nesse contexto, a auditoria de enfermagem, pode se constituir importante instrumento de gestão para a organização e implantação de rotinas que garantam possuir Registros de Enfermagem de forma adequada e válida, de modo a reduzir a aplicação de glosa nos serviços de Home Care.

Palavras chave: Registros de Enfermagem; Auditoria de Enfermagem; Serviços de Assistência Domiciliar

\begin{abstract}
Objective: To investigate the scientific production related to audit nursing, analyzing their role in nursing registration organization in Home Care Services. Method: This is a literature narrative review. Data were collected using the database Scientific Electronic Library Online ( SciELO ); Latin American and Caribbean Health Sciences ( LILACS); Health Virtual Library ( BSV), as well as books, dissertations and theses found in the Health Library of Federal University of Bahia, with a combination of descriptors: nursing records, nursing audit, home care service . Results: We selected 14 articles published from 2001 to 2015. The results were categorized into the following groups: "Audit of health services and nursing audit"; "Characteristics of nursing records"; "Historical and operational aspects of home care services"; "The main reasons for rejections in home care." Conclusion: The literature review showed that the Home Care Services shall be provided with comprehensive health services, supporting clients in their homes, allowing care safe, comfortable and humane way. In this context, the audit of nursing can be an important management tool for the organization and implementation of routines to ensure possess Nursing records properly and valid, in order to reduce the application of disallowance in Home Care Services.
\end{abstract}

Key words: Nursing Records; Nursing Audit; Home Care Services. 


\section{INTRODUÇÃO}

A auditoria em saúde foi idealizada por profissionais médicos, que buscavam proporcionar um atendimento de melhor qualidade aos clientes, já que a auditoria pretende identificar as não conformidades na prestação dos cuidados prestados, propõe ações que visam evitar a prática ineficiente e ineficaz, compreendendo os processos de trabalho, procedimentos e rotinas e o alinhamento destes com as normas legais e institucionais estabelecidas'.

Nesse contexto, a auditoria de enfermagem surge como um processo fundamental tanto no âmbito hospitalar, quanto no domiciliar, promovendo o controle do atendimento, compreendendo desde os registros dos cuidados de enfermagem até a melhor capacitação da equipe multidisciplinar envolvida no processo ${ }^{2}$.

A auditoria de enfermagem avalia a qualidade da assistência de enfermagem prestada analisando as anotações registradas no prontuário do paciente. Os registros de enfermagem são, portanto, importante meio de comunicação para toda a equipe, pois além de mostrar as ações realizadas, possibilita a continuidade da assistência prestada ao enfermo ${ }^{3}$. Reitera-se que o prontuário é um documento valioso para $\circ$ paciente e para a equipe que $\circ$ assiste, assim como para as instituições de saúde, o ensino, e a pesquisa, também podendo ser considerado instrumento de defesa legal ${ }^{4}$.

Diante disso, as informações contidas nos prontuários precisam ser claras e objetivas, proporcionando o entendimento efetivo daquilo que ocorreu com o paciente em cada período de trabalho. Registra-se que na implementação de auditorias, costuma ser identificada, inúmeras vezes, a ausência de registros ou ainda a presença de informações descritas de forma indevida, incompleta, inconsistente, ilegível, sem objetividade, fora da legalidade dentre outras não conformidades 5 .

Na atualidade muitos serviços de saúde vêm ampliando a participação na assistência à saúde, através do Home Care, que significa atenção à saúde no domicílio. Essa modalidade assistencial surgiu, de forma organizada, no início da década de 1990, seguindo um modelo alternativo e complementar ao modelo hospitalar. Dessa maneira o Home Care é compreendido como um serviço que desenvolve ações de saúde no domicílio do paciente, utilizando-se de uma equipe multiprofissional, visando a promoção da saúde, a prevenção dos riscos, associados a internação hospitalar e manutenção ou restauração da saúde, de maneira a favorecer o paciente $\circ$ restabelecimento possível da sua autonomia ${ }^{6}$.

Assim, a importância do Home Care consiste em dispor de serviços de saúde completos, para dar suporte aos pacientes em seus próprios domicílios, permitindo que indivíduos que necessitam de cuidados para enfermidades, à longo prazo ou efetivamente crônicos, para que os tenha de forma segura, confortável e humanizada no seu próprio ambiente familiar ${ }^{7}$.

Na auditoria de enfermagem, são detectadas ausências de dados fundamentais para o esclarecimento das ações realizadas bem como registros feitos de forma indevida. Grande parte do pagamento de materiais, medicamentos, procedimentos e outros serviços estão vinculados aos registros de enfermagem. Devido às anotações de enfermagem em sua maioria serem inconsistentes, ilegíveis e subjetivas, a prática de glosar itens do faturamento das contas hospitalares tem sido significativa para o orçamento dos Home Care ${ }^{5}$.

As glosas ou correções são aplicadas quando qualquer situação gerar dúvidas em relação às regras e práticas adotadas pelo Home Care. Quando elas ocorrem, observa-se conflito na relação entre convênio (plano de saúde) e prestador de serviços (instituição). Quando as instituições de cuidado de saúde têm os valores dos serviços prestados glosados pelas operadoras de planos de saúde, elas podem lançar mão de recursos, denominados recursos de glosas, a fim de recuperar suas perdas econômicas ${ }^{8}$.

Para tanto, o objetivo geral do estudo consiste em revisar a produção científica relacionada a auditoria de enfermagem, analisando o seu papel na organização do registro de enfermagem nos serviços de Home Care. 


\section{MÉTODOS}

Trata-se de uma revisão narrativa de literatura. A revisão narrativa é caracterizada como um processo de descrição do estado da arte de um assunto específico, sob o ponto de vista teórico ou contextual. Este tipo de revisão não fornece uma metodologia para a busca das referências, das fontes de informação utilizadas, nem dos critérios usados na avaliação e seleção dos trabalhos. Constituem, basicamente, da análise da literatura, da interpretação e análise crítica pessoal do pesquisador. As revisões narrativas possibilitam a aquisição e atualização de conhecimento sobre um determinado tema em curto período de tempo; no entanto, não possuem metodologia que viabilize a reprodução dos dados e nem trazem respostas quantitativas para determinados questionamentos?.

A revisão da literatura científica foi realizada através de consulta à bibliotecas virtuais e bases de dados como Scientific Electronic Library Online (SCIELO), Literatura Latino Americana e do Caribe em ciências da saúde (LILACS), Biblioteca Virtual de Saúde (BSV), além de livros, dissertações e teses encontradas no acervo da Biblioteca Universitária de Saúde da Universidade Federal da Bahia. Os termos utilizados nas buscas foram "registros de enfermagem", "auditoria em saúde", "serviço de Home Care", selecionados após consulta aos Descritores em Ciências da Saúde (DeCS). A coleta foi realizada no segundo semestre de 2015. Foram incluídos neste estudo, os artigos publicados no período de 2001 a 2015, na língua portuguesa, disponíveis na íntegra e gratuitos. Inicialmente foram lidos os títulos e resumos dos artigos encontrados nas buscas, sendo excluídos aqueles que não estavam disponíveis na íntegra, não eram de livre acesso ou que não se aproximavam com o objetivo proposto no estudo. Ao final da etapa de leitura dos textos completos, foram selecionados 14 artigos para compor o corpus documental da presente revisão.

A análise dos dados partiu da construção de uma matriz de extração de dados que continha as seguintes variáveis: "Autor/ano"; "Objetivo do estudo"; "Tipo de Estudo"; "Instrumento de Pesquisa" e "População de Estudo". Após isso, foram elaboradas as seguintes categorias para apresentação e discussão dos resultados: "Auditoria de serviços de saúde e auditoria de enfermagem"; "Características dos registros de enfermagem"; "Aspectos históricos e operacionais dos serviços de Home Care"; "Principais motivos para glosas em Home Care".

\section{RESULTADOS}

O valor total gasto com internações hospitalares em homens na faixa etária de 20 a 59 anos de idade no Sistema Único de Saúde em 2010 no Estado da Bahia foi $\mathrm{R} \$ 110.093 .299,79$, que representou $18,8 \%$ do total gasto com internações hospitalares.

Os grupos de causas de hospitalização mais frequentes na referida população de estudo naquele ano foram, respectivamente: causas externas, doenças do

Quadro 1. Caracterização das pesquisas utilizadas na elaboração dos resultados, 2015.

\begin{tabular}{|c|c|c|c|c|}
\hline Autor/ano & Objetivo & $\begin{array}{l}\text { Tipo de } \\
\text { Estudo }\end{array}$ & $\begin{array}{l}\text { Instrumento de } \\
\text { Pesquisa }\end{array}$ & $\begin{array}{l}\text { População de } \\
\text { Estudo }\end{array}$ \\
\hline $\begin{array}{l}\text { BAZZANELLA; } \\
\text { SLOB, (2013) }\end{array}$ & $\begin{array}{l}\text { Identificar a relação } \\
\text { da auditoria com a } \\
\text { gestão de } \\
\text { qualidade. }\end{array}$ & $\begin{array}{l}\text { Revisão } \\
\text { bibliográfica. }\end{array}$ & $\begin{array}{l}\text { Análise de } \\
\text { artigos } \\
\text { científicos. }\end{array}$ & - \\
\hline $\begin{array}{l}\text { BORSATO et al, } \\
(2012)\end{array}$ & $\begin{array}{l}\text { Avaliar a qualidade } \\
\text { das anotações de } \\
\text { enfermagem em } \\
\text { terapia intensiva de } \\
\text { um hospital } \\
\text { universitário. }\end{array}$ & $\begin{array}{l}\text { Pesquisa } \\
\text { descritivo- } \\
\text { quantitativa. }\end{array}$ & $\begin{array}{l}\text { Coleta de } \\
\text { dados } \\
\text { secundários. }\end{array}$ & $\begin{array}{l}\text { Relatórios da } \\
\text { avaliação da } \\
\text { qualidade das } \\
\text { anotações de } \\
\text { enfermagem } \\
\text { realizada em } \\
2009 \text {. }\end{array}$ \\
\hline
\end{tabular}


Quadro 1. Caracterização das pesquisas utilizadas na elaboração dos resultados, 2015. (continuação)

\begin{tabular}{|c|c|c|c|c|}
\hline Autor/ano & Objetivo & $\begin{array}{l}\text { Tipo de } \\
\text { Estudo }\end{array}$ & $\begin{array}{l}\text { Instrumento de } \\
\text { Pesquisa }\end{array}$ & $\begin{array}{l}\text { População de } \\
\text { Estudo }\end{array}$ \\
\hline $\begin{array}{l}\text { LUCENA et al, } \\
(2011)\end{array}$ & $\begin{array}{l}\text { Abordar o mais } \\
\text { recente serviço de } \\
\text { cuidados em saúde, } \\
\text { o Home Care, } \\
\text { apresentando a } \\
\text { qualidade deste } \\
\text { serviço. }\end{array}$ & $\begin{array}{l}\text { Revisão } \\
\text { bibliográfica. }\end{array}$ & $\begin{array}{l}\text { Análise de } \\
\text { artigos } \\
\text { científicos. }\end{array}$ & - \\
\hline $\begin{array}{l}\text { PEREIRA; } \\
\text { MIRANDA; } \\
\text { COSTA, }(2011)\end{array}$ & $\begin{array}{l}\text { Compreender o } \\
\text { processo de } \\
\text { auditoria em } \\
\text { enfermagem e suas } \\
\text { interfaces com o } \\
\text { cuidado. }\end{array}$ & $\begin{array}{l}\text { Revisão } \\
\text { bibliográfica. }\end{array}$ & $\begin{array}{l}\text { Análise de } \\
\text { artigos } \\
\text { científicos. }\end{array}$ & 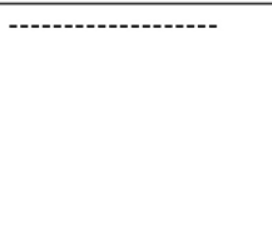 \\
\hline $\begin{array}{l}\text { SOUZA; } \\
\text { DYNIEWICCZ; } \\
\text { KALINOWSKI, } \\
(2010)\end{array}$ & $\begin{array}{l}\text { Conhecer a prática } \\
\text { da enfermeira em } \\
\text { auditoria em saúde. }\end{array}$ & $\begin{array}{l}\text { Revisão } \\
\text { bibliográfica. }\end{array}$ & $\begin{array}{l}\text { Análise de } \\
\text { artigos } \\
\text { científicos. }\end{array}$ & - \\
\hline $\begin{array}{l}\text { D'INOCCENZO; } \\
\text { SETZ, (2009) }\end{array}$ & $\begin{array}{l}\text { Avaliar por meio da } \\
\text { auditoria, a } \\
\text { qualidade dos } \\
\text { registros de } \\
\text { enfermagem nos } \\
\text { prontuários de } \\
\text { pacientes atendidos } \\
\text { em unidades de um } \\
\text { hospital universitário. }\end{array}$ & $\begin{array}{l}\text { O estudo é } \\
\text { descritivo, } \\
\text { retrospectivo. }\end{array}$ & $\begin{array}{l}\text { Coleta de } \\
\text { dados do } \\
\text { prontuário. }\end{array}$ & $\begin{array}{l}424 \text { prontuários } \\
\text { analisados entre } \\
\text { novembro de } 2006 \\
\text { a janeiro de } 2007 .\end{array}$ \\
\hline \multirow[t]{2}{*}{$\begin{array}{l}\text { FERREIRA et al., } \\
(2009)\end{array}$} & $\begin{array}{l}\text { Identificar o impacto } \\
\text { causado pelo não } \\
\text { registro de } \\
\text { enfermagem } \\
\text { contrapondo às } \\
\text { eventuais glosas, }\end{array}$ & $\begin{array}{l}\text { Pesquisa } \\
\text { descritiva e } \\
\text { exploratória } \\
\text { de } \\
\text { abordagem } \\
\text { qualitativa e }\end{array}$ & $\begin{array}{l}\text { Pesquisa } \\
\text { documental de } \\
\text { materiais. }\end{array}$ & Prontuários \\
\hline & $\begin{array}{l}\text { evidenciando os } \\
\text { principais tipos } \\
\text { decorrentes destes } \\
\text { registros. }\end{array}$ & quantitativa. & & \\
\hline $\begin{array}{l}\text { GODOl et al, } \\
(2008)\end{array}$ & $\begin{array}{l}\text { Avaliar os } \\
\text { indicadores mais } \\
\text { freqüentes nas } \\
\text { discussões } \\
\text { hospitalares, através } \\
\text { de uma avaliação } \\
\text { dos prontuários } \\
\text { hospitalares e das } \\
\text { anotações de } \\
\text { enfermagem, para } \\
\text { diminuição destes } \\
\text { índices de maneira } \\
\text { global. }\end{array}$ & $\begin{array}{l}\text { Pesquisa } \\
\text { descritiva, } \\
\text { análise } \\
\text { retrospectiva. }\end{array}$ & $\begin{array}{l}\text { Instrumentos, } \\
\text { desenvolvidos } \\
\text { pelas } \\
\text { pesquisadoras. }\end{array}$ & $\begin{array}{l}\text { Prontuários } \\
\text { hospitalares }\end{array}$ \\
\hline $\begin{array}{l}\text { ALVES et al, } \\
(2007)\end{array}$ & $\begin{array}{l}\text { Conhecer o processo } \\
\text { de trabalho do } \\
\text { enfermeiro em um } \\
\text { serviço de Home } \\
\text { Care na cidade de } \\
\text { Belo Horizonte. }\end{array}$ & $\begin{array}{l}\text { Estudo } \\
\text { qualitativo. }\end{array}$ & $\begin{array}{l}\text { Entrevista semi- } \\
\text { estruturada. }\end{array}$ & $\begin{array}{l}\text { Enfermeiros que } \\
\text { trabalham na } \\
\text { gerência e na } \\
\text { prestação de } \\
\text { cuidados }\end{array}$ \\
\hline
\end{tabular}


Quadro 1. Caracterização das pesquisas utilizadas na elaboração dos resultados, 2015. (continuação)

\begin{tabular}{|c|c|c|c|c|}
\hline Autor/ano & Objetivo & $\begin{array}{l}\text { Tipo de } \\
\text { Estudo }\end{array}$ & $\begin{array}{l}\text { Instrumento de } \\
\text { Pesquisa }\end{array}$ & $\begin{array}{l}\text { População de } \\
\text { Estudo }\end{array}$ \\
\hline $\begin{array}{l}\text { LUZ; MARTINS; } \\
\text { DYNEWICCZ, } \\
(2007)\end{array}$ & $\begin{array}{l}\text { Identificar a } \\
\text { qualidade dos } \\
\text { registros de } \\
\text { enfermagem em } \\
\text { contas hospitalares }\end{array}$ & $\begin{array}{l}\text { Pesquisa } \\
\text { descritiva e } \\
\text { exploratória } \\
\text { de } \\
\text { abordagem } \\
\text { qualitativa e } \\
\text { quantitativa }\end{array}$ & $\begin{array}{l}\text { Pesquisa } \\
\text { documental de } \\
\text { materiais. }\end{array}$ & Prontuários \\
\hline $\begin{array}{l}\text { MATSUDA et al, } \\
(2006)\end{array}$ & $\begin{array}{l}\text { Analisar as } \\
\text { anotações/registros } \\
\text { efetuadas pela } \\
\text { equipe de } \\
\text { enfermagem de um } \\
\text { hospital-escola. }\end{array}$ & $\begin{array}{l}\text { Estudo do tipo } \\
\text { documental. }\end{array}$ & Formulário. & $\begin{array}{l}\text { Analisou } 124 \\
\text { anotações/registros } \\
\text { de enfermagem } \\
\text { ( } 51 \text { de enfermeiros } \\
\text { e } 73 \text { de auxiliares } \\
\text { de enfermagem). }\end{array}$ \\
\hline \multirow[t]{2}{*}{$\begin{array}{l}\text { RODRIGUES; } \\
\text { PERROCA; } \\
\text { JERICÓ, (2004) }\end{array}$} & $\begin{array}{l}\text { Investigar os fatores } \\
\text { intervenientes nas } \\
\text { glosas ocorridas em } \\
\text { um hospital de } \\
\text { ensino. }\end{array}$ & $\begin{array}{l}\text { Estudo } \\
\text { retrospectivo } \\
\text { de natureza } \\
\text { exploratória } \\
\text { descritiva. }\end{array}$ & $\begin{array}{l}\text { A coleta de } \\
\text { dados incluiu as } \\
\text { glosas } \\
\text { identificadas a } \\
\text { partir de seus } \\
\text { recursos, junto } \\
\text { a duas } \\
\text { operadoras de } \\
\text { planos de } \\
\text { saúde, no } \\
\text { período de } \\
\text { janeiro a março }\end{array}$ & $\begin{array}{l}17.324 \text { itens } \\
\text { glosados nos } 85 \\
\text { recursos de glosas } \\
\text { analisados }\end{array}$ \\
\hline & & & de 2003 & \\
\hline $\begin{array}{l}\text { OLIVEIRA, } \\
(2003)\end{array}$ & $\begin{array}{l}\text { Identificar o impacto } \\
\text { causado pelo não } \\
\text { registro de } \\
\text { enfermagem } \\
\text { contrapondo às } \\
\text { eventuais glosas, } \\
\text { evidenciando os } \\
\text { principais tipos } \\
\text { decorrentes destes } \\
\text { registros. }\end{array}$ & $\begin{array}{l}\text { Pesquisa } \\
\text { descritiva e } \\
\text { exploratória. }\end{array}$ & $\begin{array}{l}\text { O estudo se } \\
\text { materializou } \\
\text { por meio } \\
\text { documental Foi } \\
\text { realizado em } \\
\text { um serviço de } \\
\text { urologia de um } \\
\text { hospital } \\
\text { privado do } \\
\text { município de } \\
\text { Niterói/RJ. }\end{array}$ & Prontuários. \\
\hline $\begin{array}{l}\text { AMARAL et al, } \\
(2001)\end{array}$ & $\begin{array}{l}\text { Analisar o conteúdo } \\
\text { histórico e utilização } \\
\text { da Assistência } \\
\text { Domiciliar à Saúde } \\
\text { (ADS) como } \\
\text { instrumento } \\
\text { minimizador dos } \\
\text { custos e das } \\
\text { complicações } \\
\text { advindos da } \\
\text { hospitalização. }\end{array}$ & $\begin{array}{l}\text { Revisão } \\
\text { bibliográfica. }\end{array}$ & $\begin{array}{l}\text { Análise de } \\
\text { artigos } \\
\text { científicos. }\end{array}$ & 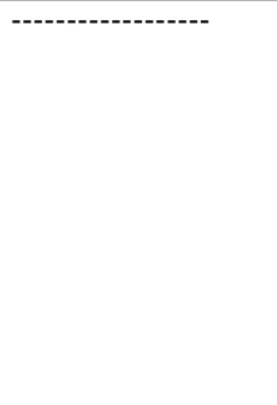 \\
\hline
\end{tabular}

Fonte: Elaborado pelos autores (2015). 


\section{Auditoria de serviços de saúde e auditoria de enfermagem}

A auditoria em serviços de saúde teve seu início com a mudança do enfoque contábil para o administrativo, que buscava avaliar a eficácia e a efetividade da aplicação dos controles internos. A auditoria pode ser considerada uma área do conhecimento relacionada ao monitoramento e avaliação da qualidade assistencial, favorecendo as instituições no planejamento e programação de insumos e recursos ${ }^{10}$.

No Brasil, a auditoria em saúde foi instituída em pelo Instituto Nacional de Assistência Médica da Previdência Social (INAMPS), em 1984, que a definiu como um conjunto de ações administrati $\neg$ vas, técnicas, que buscam a caracterização definida do desempenho assistencial, efetuado pelos integrantes de todos os níveis de execução, especialmente aqueles ligados às unidades médico-assistenciais próprias, contratadas, conveniadas e em regime de participação da empresa'.

A auditoria de enfermagem deriva da filosofia da gestão da qualidade total, que buscar promover - controle de todos os passos do processo de atenção ao paciente, incluindo ações de correção, mediante a educação da equipe multidisciplinar, reorganização de processos de trabalho e implantação de protocolos e rotinas, que visam a melhoria do atendimento ${ }^{1}$.

A auditoria inicia na enfermagem com o intuito de avaliar aspectos técnicos, éticos e administrativos do trabalho da equipe de saúde. $O$ elevado número de estudos na área da auditoria, realizados por enfermeiros demonstram um maior envolvimento destes profissionais, com a análise da qualidade dos cuidados de enfermagem prestados ao paciente.

A regulamentação da Enfermagem ocorreu através da Lei 7.498/86 que dispõe sobre o Exercício da Enfermagem e posteriormente, a Resolução do COFEN 266/01 dispõe sobre as atividades do Enfermeiro Auditor. $\bigcirc$ Enfermeiro Auditor tem a função de organizar, dirigir, coordenar, planejar, prestar consultoria/auditoria e relatórios sobre os serviços de Auditoria de Enfermagem, fazendo com que o Auditor de saúde atue também no planejamento, execução e avaliação da programação de saúde ${ }^{12}$ (BRASIL, 2001). Além das disposições propostas pela Resolução do COFEN $n^{\circ}$ 266/2001, o Código de Ética dos profissionais de Enfermagem estabelece os princípios, deveres e proibições e pode orientar a conduta ética desses profissionais, sendo estes, auditores ou não, contribuindo direta ou indiretamente para o processo de auditoria em enfermagem ${ }^{13}$.

A Auditoria de Enfermagem é o processo pelo qual é feita uma avaliação das atividades de enfermagem, trata-se da análise minuciosa da qualidade da assistência prestada ao paciente. Pode ser realizada por meio de análise dos prontuários, verificação da conciliação entre o procedimento realizado e os itens da conta hospitalar, visitas, entre outros ${ }^{11}$.

A Auditoria de Enfermagem avalia a qualidade da assistência de enfermagem prestada, sendo verificada através das anotações no prontuário do paciente ou das próprias condições deste. Os registros de enfermagem são um importante meio de comunicação para toda a equipe, pois além de mostrar as ações realizadas, possibilita uma continuidade da assistência ao enfermo ${ }^{3}$.

\section{Características dos registros de enfermagem}

Os registros são realizados através do prontuário, que é um documento legal do paciente, sendo de responsabilidade da equipe de saúde. Nele, devem estar contidas as condutas médicas e de enfermagem, realizadas durante a internação do paciente, desde a sua admissão até a sua alta ${ }^{11}$.

Os registros de enfermagem são constituídos por anotações referentes à assistência prestada, realizadas pelos profissionais no ato de suas atividades. São consideradas fontes escritas de informações, relativas às condições do paciente, aos cuidados prestados e aos resultados do alcançados ${ }^{8}$.

Os cuidados de enfermagem são avaliados através dos registros, que são as anotações de enfermagem, no qual, devem conter dados objetivos, claros, checagem de medicamentos e todos os procedimentos realizados, com identificação do profissional através do nome e número do registro do COREN. O Registro de Enfermagem pode avaliar 
a qualidade da assistência e garantir o respaldo legal ao profissional ${ }^{1}$.

A anotação no prontuário é uma forma de comunicação da equipe multiprofissional, o qual serve de base para elaboração de condutas assistenciais para os pacientes, avaliação da assistência prestada e da evolução do mesmo, além de contribuir para a auditoria4. As anotações devem ser expressas de forma legível e sem rasuras, para uma boa interpretação dos demais profissionais, entretanto se forem ilegíveis e incompreensíveis, tornam-se inúteis ${ }^{8}$.

O registro representa a comunicação escritas dos fatos essenciais, deve ser claro e conciso, elaborado em linguagem compreensível e expresso de maneira inteligível ${ }^{11}$. A Resolução Cofen 311/2007, no art. 72 , trata da responsabilidade e dever de registrar informações inerentes e indispensáveis ao processo de cuidar, deve ser feito de forma clara, objetiva e completa $^{13}$.

Nas auditorias, os registros de enfermagem aparecem como realizados de forma indevida, inconsistentes, subjetivas, ilegíveis, ou até mesmo sem registro. Desta forma, são analisados e quando passíveis de dúvida, quanto aos procedimentos realizados ou a falta de registro, pode incidir em glosas das contas 5 .

\section{Aspectos históricos e operacionais dos serviços de home care}

O movimento do Home Care surgiu nos Estados Unidos e Europa, no contexto da Segunda Guerra Mundial. Nos Estados Unidos, enfermeiras se reuniam e passavam a atender e cuidar dos pacientes em casa. Já na Europa, após vários hospitais terem sido bombardeados, houve a necessidade dos médicos irem até os pacientes. Essa iniciativa foi o primeiro passo no desenvolvimento do serviço da medicina domiciliar ${ }^{6}$.

Esse tipo de assistência domiciliar está assumindo grande importância no cenário internacional, seja como uma forma de redução dos custos de internação hospitalar, seja para proporcionar segurança, bem estar e conforto para o paciente em seu próprio domicílio. O Home Care deverá firmar- se definitivamente no século $X X I$, ampliando sua abrangência, pra diversas especialidades médicas e áreas de atuação de profissionais da saúde, com ênfase para os enfermeiros, dado seu protagonismo nos processos de cuidadob.

Espera-se que $\bigcirc$ atendimento domiciliar acelere a recuperação do paciente e promova a redução dos custos, sendo uma maneira mais humana para os portadores de doenças crônicas ou de longa duração e mais viável financeiramente. Outro fator importante é que o paciente ficará afastado do risco de infecções hospitalares e do estresse da internação, sendo beneficiado com a atenção de toda equipe multiprofissional e de todos recursos necessários ${ }^{14}$.

No Brasil o primeiro sistema de atendimento domiciliar foi criado no Hospital do Servidor Público Estadual de São Paulo em 1967, tendo como objetivo principal reduzir o número de leitos ocupados, englobando nestes atendimentos cuidados de baixa complexidade clínica. Infelizmente não existem dados concretos sobre a data exata do surgimento de empresas de Home Care no país ${ }^{6}$.

A expansão do Home Care no Brasil teve forte impulso após sancionada a Lei $n^{\circ} 10.424$ de 15 de abril de 2002, que cria e define as responsabilidades desse serviço no âmbito do Sistema Único de Saúde (SUS). Esta legislação estabelece os procedimentos médicos, de enfermagem, fisioterapêuticos, psicológicos, de assistência social, dentre outros, necessários ao cuidado integral dos pacientes em domicílio. Os atendimentos na internação domiciliar são realizados por equipe multidisciplinar que atua nos níveis preventivo, terapêutico e reabilitador ${ }^{15}$.

\section{Principais motivos para glosas em home care}

Glosa significa $\circ$ cancelamento parcial ou total do orçamento, ou seja, refere-se aos itens que o auditor do plano de saúde não considera cabível ao pagamento. São aplicadas quando geram dúvidas em relação à regra e prática adotada pela instituição de saúde ${ }^{3}$.

As instituições de saúde quando tem seus procedimentos glosados pelas operadoras de saúde, podem recorrer das glosas, com a finalidade 
de recuperar suas perdas econômicas pelos descontos que consideram indevidos, contudo devem auditar e avaliar os procedimentos de registro, de modo a detectar e corrigir erros que impactam no faturamento ${ }^{5}$.

As glosas representam importante problema na auditoria de enfermagem em serviços de Home Care. Os resultados da revisão de literatura apontam como principais causas de glosas a falta de checagem na prescrição médica e de enfermagem, desatenção na observância à evolução descrita nos registros dos pacientes, dificuldade na interpretação devido a letra ilegível e rasuras, falta de registro de procedimento de fisioterapia, falta de registros dos antibióticos, incompletude nos horários e datas nas evoluções e ausência da assinatura, número do registro e carimbos nas evoluções.

As glosas por falta de checagem na prescrição médica e de enfermagem e por desatenção nas observâncias às informações contidas na evolução são comuns nos serviços de Home Care. A checagem garante se um medicamento foi administrado ou procedimento foi realizado, mas para isso deve ser feita de maneira correta, ou seja, com um traço na diagonal sobre o horário na cor vermelha nos turnos da manhã e da tarde e na cor azul no turno da noite. Em caso de soluções, deve-se colocar o horário e o volume infundido. Quando não realizados, os horários devem ser circulados e justificados ${ }^{8}$.

Os procedimentos e medicações devem ser checados nos prontuários para evitar o não pagamento de gastos efetivamente realizados, evitando as glosas, que reduzem de forma expressiva a capacidade financeira da instituição. As instituições, para reduzir os seus prejuízos, elaboram recursos de glosas embasados em justificativas dos profissionais envolvidos no cuidado, o que nem sempre é acatado. Constata-se, então, que os registros de enfermagem influenciam diretamente no controle econômico, evidenciando a importância das checagens nas prescrições pelos profissionais. Considerando que existem nos Home Care protocolos e rotinas que tem por objetivo definir claramente $\circ$ preenchimento dos Registros de Enfermagem e prontuários, a Auditoria em Serviço de Saúde pode contribuir para o realinhamento do processo de trabalho, através da identificação das causas do desvio de comportamento, propondo ao gestor, ações que visam a correção das condutas e sua efetiva realização de acordo com as normas institucionais ${ }^{11}$.

Quanto às glosas decorrentes da letra ilegível e rasuras, estas se relacionam à dificuldade de entendimento e interpretação por conta da escrita inelegível e rasuras realizadas pelos profissionais nos prontuários, o que pode gerar riscos aos pacientes, decorrente de erro em aplicação ou falta de medicações, dosagem errada, dentre outros. O prontuário é um documento legal em que não se permitem rasuras. No caso de registros equivocados, deve-se utilizar o termo "digo", ou "registro incorreto" entre vírgulas, conforme estabelecido nos Procedimentos Operacionais Padrão (POP) da instituição. Quanto à ilegibilidade, os profissionais da área de enfermagem precisam estar conscientes de que a difícil compreensão dos registros possibilita a interrupção do processo de comunicação com a equipe multiprofissional e isso pode causar danos à assistência prestada ao paciente e dificultar a defesa profissional em casos de processos judiciais, além de ser motivo de glosa pela falta de informações referente ao tratamento realizado ${ }^{4}$.

Os problemas relacionados ao registro de procedimentos de fisioterapia são atribuídos à falta de preenchimento do cabeçalho na folha disponibilizada para anotações do atendimento realizado em Home Care. Além disso, também são comuns em prontuários que traduzem os atendimentos de fisioterapia a ausência de informações completas, como o tipo de atendimento dado ao paciente ${ }^{8}$.

Outra questão que se relaciona à ocorrência de glosa se refere à falta dos registros dos antibióticos, uma vez que este medicamento é de uso controlado e sua liberação deve ser precedida de prescrição médica, sendo que sua dosagem deve ser liberada de forma específica. A administração de antimicrobianos de forma não processual e legalmente estabelecida se constitui em irregularidade passível de aplicação de instrumento de polícia por parte da Vigilância Sanitária, o que causaria ainda mais perda financeira para instituição. Por esse motivo, a realização de uma Auditoria Interna de Serviço de Saúde, com a participação do farmacêutico da instituição, tornase necessária e urgente, para identificar claramente 
os desvios de conduta, o conhecimento técnico da equipe a cerca desse fato, analisar os procedimentos operacionais e sua conformidade com a norma legal, de modo a propor o realinhamento dos protocolos, do processo de trabalho, a capacitação da equipe e instrumentos de avaliação que permitam a gestão monitorar o cumprimento das determinações da Agência Nacional de Vigilância Sanitária ${ }^{16}$.

As anotações que demonstram a realização adequada da terapêutica medicamentosa com resultados de intervenções de enfermagem, orientações, cuidados prestados de forma sistematizada e coerente, são evidências objetivas da qualidade da assistência que está sendo prestada ao cliente.

No que se referem à falta dos horários, datas, assinaturas, número do registro do Conselho e carimbos nas evoluções, estas são não conformidades injustificadas, considerando que $\circ$ profissional que realiza os procedimentos assistenciais tem a obrigação de se identificar claramente em qualquer documento relacionado com a assistência do paciente. As assinaturas nas evoluções estão sendo substituído por rubrica ou pelo primeiro nome, sem o número do Conselho de Classe, o que impede a identificação da categoria profissional, responsável pela ação. Esta inconformidade contraria as normas estabelecidas para $\circ$ registro dos procedimentos assistenciais, podendo a Auditoria de Serviço de Saúde ser um instrumento valioso na readequação deste processo de trabalho ${ }^{17}$.

Os registros de enfermagem estão deficientes, embora a resolução COFEN $311 / 2007$, o Código de Ética dos Profissionais de Enfermagem afirme, que é direito, dever e responsabilidade do enfermeiro registrar informações relativas ao processo de cuidar do indivíduo, no prontuário e em outros documentos próprios da enfermagem ${ }^{13}$.

A identificação do profissional e da sua categoria é um elemento imprescindível ao término da elaboração dos registros de enfermagem, visto que estes são documentos que sofrem implicações de ordem ética e legal ${ }^{15}$. Toda anotação deve ser precedida de horário, colocando-se a data na primeira anotação do dia ${ }^{17}$.

\section{CONSIDERAÇÕES FINAIS}

A revisão da literatura realizada nesse estudo apontou que os serviços de Home Care tem por fim dispor de serviços de saúde integrais, dando suporte aos clientes à longo prazo ou efetivamente crônicos, em seus domicílios, permitindo cuidados de forma segura, confortável e humanizada no seu próprio ambiente familiar. Nesse contexto, a auditoria de saúde, especificamente a auditoria de enfermagem, pode se constituir importante instrumento de gestão para a organização e implantação de rotinas que garantam possuir Registros de Enfermagem de forma adequada e válida, de modo a reduzir a aplicação de glosa nos serviços de Home Care.

Desse modo, os resultados mostraram que anotação objetiva e criteriosa é garantia de menores perdas econômicas, além de ser um requisito válido para a defesa legal no ponto de vista jurídico. Por outro lado, anotações incompletas e ilegíveis ou a ausência delas são indícios de glosas e de falta de qualidade da assistência de enfermagem, além de ser reflexo do que é realizado na prática implicando, assim, em questões éticas.

\section{CONTRIBUIÇÕES DOS AUTORES}

Dantas IC participou da concepção, delineamento, busca e análise qualitativa dos dados da pesquisa, interpretação dos resultados, redação do artigo científico. Duarte MG e Souza EA participaram da concepção e delineamento, interpretação dos resultados e redação do artigo científico. Pinto Junior EP participou da concepção e delineamento, interpretação dos resultados, redação e encaminhamento do artigo científico.

\section{CONFLITOS DE INTERESSES}

Nenhum conflito financeiro, legal ou político envolvendo terceiros (governo, empresas e fundações privadas, etc.) foi declarado para nenhum aspecto do trabalho submetido (incluindo mas não limitandose a subvenções e financiamentos, conselho consultivo, desenho de estudo, preparação de manuscrito, análise estatística, etc).

\section{REFERÊNCIAS}

1. Souza LAA, Dyniewicz AM, Kalinowski LC. Auditoria: uma abordagem histórica e atual. RAS. 2010;12(47):71-78.

2. Paim CRP, Ciconelli RM. Auditoria de avaliação da qualidade dos serviços de saúde. RAS. 2007;9(36):85-92. 
3. Ferreira TS, Braga ALS. Auditoria de enfermagem: o impacto das anotações de enfermagem no contexto das glosas hospitalares. Aquichán. 2015;9(1):38-49.

4. Inocenzzo MD, Setz VG. Avaliação da qualidade dos registros de enfermagem no prontuário por meio da auditoria. Acta Paul. Enferm. 2009;22(3):313-317.

5. Rodrigues VA, Perroca MG, Jericó MC. Glosas hospitalares: importância das anotações de enfermagem. Arq. Ciênc. Saúde. 2004;1 1(4):210-214.

6. Lucena JBC, Guimarães JCF, Severo EA, Cruz MR, Martini A. Home care: Serviço Domiciliar em Saúde. $1^{\circ}$ Simpósio Científico FTSG. 4 a 6 out, 2011.

7. Lacerda MR, Giacomozzi CM, Oliniski SR, Truppel TC. Atenção à saúde no domicílio: modalidades que fundamentam sua prática. Saúde e Sociedade. 2006; 15(2):88-95. doi: 10.1590/S0104$\underline{12902006000200009}$

8. Borsato FG, Rossaneis MA, Haddad MCFL, Vannuchi MTO, Vituri DW. Qualidade das anotações de enfermagem em unidade de terapia intensiva de um hospital universitário. Rev. Eletr. Enf. 2012;14(3):610-7.

9. Bernardo WM, Nobre MRC, Jatene FB. A prática clínica baseada em evidências. Parte II - buscando as evidências em fontes de informação. Revista da Associação Médica Brasileira. 2004;50(1):104- 108. doi: 10.1590/S0104$\underline{42302004000100045}$

10. Pereira AS, Miranda NRR, Costa RF. Auditoria em enfermagem e suas interfaces com o cuidado: uma revisão de literatura. Percurso Acadêmico. $2011 ; 1$ (2):287-306.

11. Godoi AP, Machado CS, Lins MA, Cruz MG, Batista VM, Rosa BA. Auditoria de custo: análise comparativa das evidências de glosas em prontuário hospitalar. Rev. Inst. Ciênc. Saúde. 2008;26(4):403-408.

12. Brasil. Conselho Federal de Enfermagem. Resolução n.o 266, de 5 de outubro de 2001. Aprova as atividades do Enfermeiro Auditor. Brasília. DF. 2001.

13. Conselho Federal de Enfermagem. Código de ética os profissionais de enfermagem [Internet]. 2007 [Acesso em 10 de junho de 2015]. Disponível em: http://www.portalcoren-rs. gov.br/docs/Anexo_Resolucao_COFEN_266-2001.pdf

14. Nilcéia Noli do Amaral NN, Cunha MCB, Labronici RHDD, Oliveira ASB, Gabbai AA. Assistência domiciliar à saúde (Home Health Care): sua história e sua relevância para o Sistema de Saúde Atual. Rev. Neurociências. $2001 ; 3(9): 111$ 117.
15. Alves M, Araújo MT, Santana DM, Vieira DL. Trabalho do enfermeiro uma empresa de Home Care de Belo Horizonte, Brasil. Invest. Educ. Enf. 2007;XXV(2):96-106.

16. Brasil. Resolução RDC $n^{\circ} 20$, de 5 de maio de 2011. Dispõe sobre o controle de medicamentos à base de substâncias classificadas como antimicrobianos, de uso sob prescrição, isoladas ou em associação. Órgão emissor: ANVISA- Agência Nacional de Vigilância Sanitária. Brasília. DF. 2011.

17. Matsuda LM, Silva DMP, Évora YDM, Coimbra JAH. Anotações/registros de enfermagem: instrumento de comunicação para a qualidade do cuidado? Rev. Eletrônica Enferm. 2006;8(3):415-21. 